\title{
ELECTRIC CONSUMPTION ASSESSMENT USING SMART METER DATA AND KPI METHODOLOGY
}

\author{
A. Mutule ${ }^{1 *}$, I. Zikmanis' ${ }^{1}$, A.-M. Dumitrescu² \\ ${ }^{1}$ Institute of Physical Energetics, \\ 11 Krivu Str., Riga, LV-1006, LATVIA \\ 2 University Politehnica of Bucharest, \\ 313 Splaiul Independentei, Bucharest, RO-060042, ROMANIA \\ *e-mail: amutule@edi.Iv
}

In the modern world, many cities make use of state-of-the-art technologies for a diversity of applications. A field with very specific needs is the electric power system that deals with both large entities that govern themselves (grid operators) and the citizens. For both and all actors in between, there is an increased need for information. Steps to provide these data are always taken and several initiatives are ongoing across the world to equip residential users with last generation smart meters. However, a full deployment is still not possible. Considering this aspect, the authors propose KPIs for the specific situation when some information is available from the meters and other sources, but some is not. The study case is based on a residential area occupied mainly by university students and after an extensive measurement campaign the results have been studied and analysis methods proposed.

Keywords: electric energy, key performance indicator (KPI), load profiles, modelling approach, smart city

\section{INTRODUCTION}

People living in cities nowadays progressively take advantage of more communication technologies and multiple opportunities based on solution implementation across various sectors (e.g., transportation, services, infrastructures etc.), thus transforming their environment in a smarter one.
These advanced cities are called smart cities, which can be defined in multiple ways [1]. The collected definitions slightly differ but share overarching features - advanced connectivity using ICT, improved service system, low impact on the environment and prosperity of citizens. Although the 
concept of a smart city is fairly similar between definitions as well as implementation, the individual smart city solutions are unique for the individual city. This means that a solution carried out for one city cannot be adopted without any adjustment for another, because solutions are usually specifically designed and developed to address the local situation regarding its inhabitants, environment, infrastructure etc. [2].

The large number of the developed smart city solutions has created a need for solution evaluation and comparison. It is a challenge to provide entirely equal solution comparison. The author in [3] has provided an examination of solution evaluation through modelling approaches. One of the approaches is based on Key Performance Indicator (KPI) methodology, which is one of today's frequently used performance evaluation methods. The KPI method provides the ability to observe, adapt and improve process development through selected parameter monitoring while introducing changes. The change in key parameters is evaluated for a certain selected period to determine growth or decline in the target process. Furthermore, a hasty or inaccurate parameter selection can create a misleading KPI and develop dysfunctional behaviours and/or conclusions. To help mitigate unfavourable KPI creation, authors in [4]-[6] have detailed the process of successful KPI creation and selection.

After KPIs are defined, data are collected and comparison is made between the previously and currently collected data to determine the change over time. Fur- thermore, if multiple KPIs after examination can be categorised based on common features, the KPIs in question are collected under a specific category, formed as the assembly of different KPIs with similar characteristics. This provides the evaluation method with a large diversity and the KPI method, in general, serves as a powerful tool, which is branching into many areas of human activities.

In this paper, the KPI evaluation method is used to assess the electric energy consumption and related behaviour of student dorms located on the UPB campus in Bucharest, Romania [7]. The dorms represent a part of the city through the role of dorm inhabitants and their effects towards energy consumption based on individual user awareness [8]. The data of dorm KPI evaluation are taken from the smart meter deployment, where each dorm has a smart meter, monitoring consumption per floor. Details about this deployment can be found in [9].

To perform the KPI evaluation, the correct and altered dorm consumption situation must be compared, but considering user privacy, the exact consumption pattern cannot be used. To tackle this situation, building consumption modelling is performed using multiple information sources - user consumption surveys, yearly smart meter measurements and additional information (in Section 2.3). The created model calibrated to represent the real situation is used to test alternative scenarios impacted by user awareness and examine the feasibility of renewable energy solutions.

\section{DATA COLLECTION}

\subsection{Student Dorm}

The UPB campus contains multiple student dorms. Four of which have been impro- ved, while working under ITCity project, through smart meter system deployment, 
providing three-phase electric consumption monitoring of each floor individually.

Table 1 provides general information on the involved dorms. This information includes the number of floors per building, approximate number of inhabitants per floor and room, estimated size of inhabitant living space per floor and room, degree of renewable energy consumption share (estimated from national information [10]), the available roof space area and yearly energy consumption. The yearly energy consumption has been obtained aggregating the smart meter data, while other information is based on statistics.

Table 1. Dorm General Overview

\begin{tabular}{|c|c|c|c|c|c|c|c|c|}
\hline & \multirow{2}{*}{$\begin{array}{l}\text { No. } \\
\text { floors }\end{array}$} & \multicolumn{2}{|c|}{ Users } & \multicolumn{2}{|c|}{ Living space } & \multirow[b]{2}{*}{ RES, \% } & \multirow{2}{*}{$\begin{array}{c}\text { Available } \\
\text { roof area, } \\
\mathrm{m}^{2}\end{array}$} & \multirow{2}{*}{$\begin{array}{c}\text { Yearly energy } \\
\text { consumption, } \\
\mathrm{kWh}\end{array}$} \\
\hline & & Floor, no. & Room, no. & Floor, $\mathrm{m}^{2}$ & Room, $\mathrm{m}^{2}$ & & & \\
\hline Dorm 1 & 5 & 60 & 5 & 360 & 30 & 42.7 & 430 & 109440 \\
\hline Dorm 2 & 5 & 80 & 2 & 480 & 12 & 42.7 & 600 & 253635 \\
\hline Dorm 3 & 5 & 80 & 2 & 480 & 12 & 42.7 & 600 & 246097 \\
\hline Dorm 4 & 5 & 80 & 2 & 480 & 12 & 42.7 & 600 & 321194 \\
\hline
\end{tabular}

Across the involved dorms, situation of approximately 1500 dorm inhabitants is reflected through the data in Table 1 . This

\subsection{Consumer Habits}

The inhabitants of student dorms shape the building energy consumption, thereby their individual habits, daily activities and preferences are necessary for a proper consumption assessment. The necessary information is deducted using a statistical approach to information from Electrical Engineering Faculty webpage [11], containing 48 study group schedule, and the results of user consumption surveys filled by students.

University study group schedule provides the essential information of dorm inhabitant work day occupation that is used in the present study as a baseline. This occupation depicts the moment when the inhabitants should be at the university and not contribute to the actual building energy consumption. The study schedules provide a large occupation period variety for the inhabitants, depicting in an accurate way the diversity of the occupancy patterns in information is used to derive the consumption model and is used as a guideline for the analysis presented in Section 3.

the monitored building.

A consumption survey has been carried out to address the individual user consumption in an environment with no smart meter information. The survey results provide an insight into the individual user appliance list as well as their unique use preferences and habits. In Fig. 1, the snapshot of the conducted survey table is presented. The survey table can be divided into two main axes, the top horizontal axis representing the time divided into increments of $15 \mathrm{~min}$ utes, adding up to a 24-hour range, and the vertical axis provides a comprehensive list of appliances and their average rated power (in watts). This survey is filled out using values from 1 to $\mathrm{N}$, while the value addresses certain appliance use in a particular time period. If a value larger than 1 is used, it can indicate that the appliance power is larger than the one given in the list or that multiple similar appliances work simultaneously. 


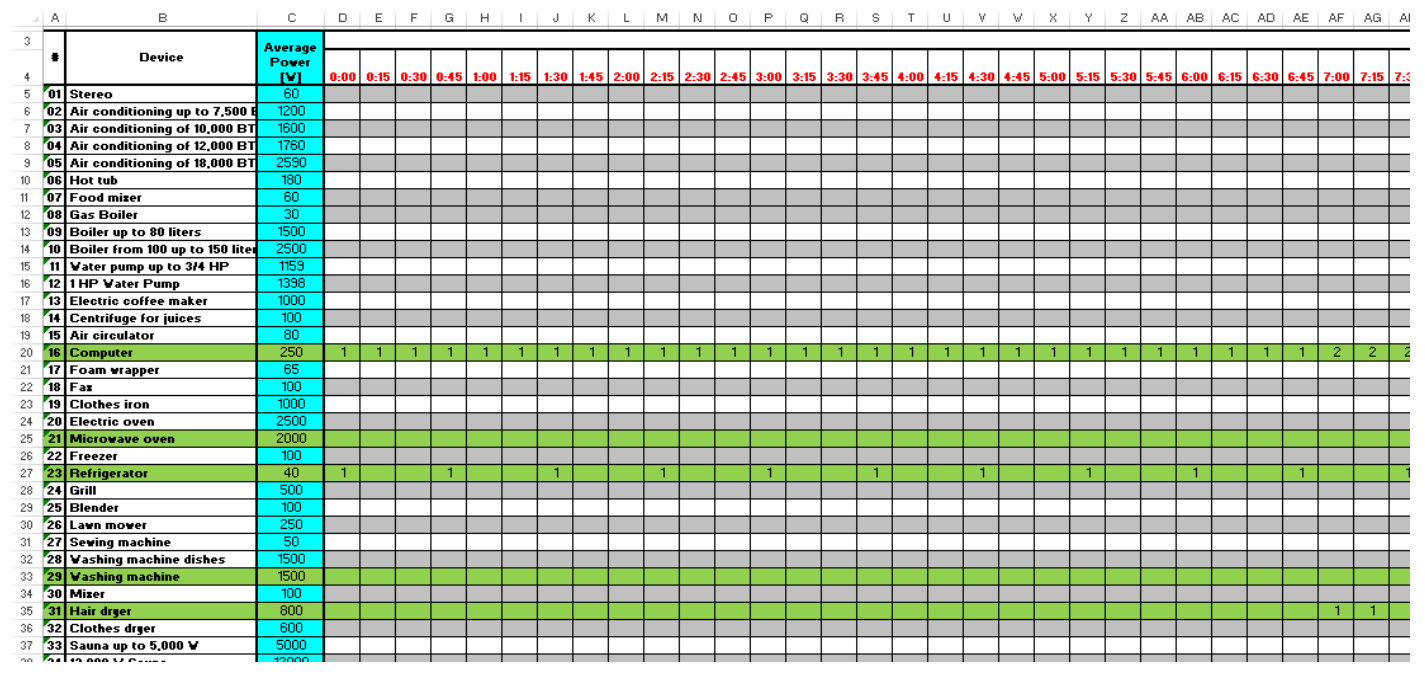

Fig. 1. Consumption survey snapshot.

The filled out surveys depict the selfassumed user consumption, thereby the user's actual consumption can differ. This information does not include detailed dayto-day habit changes, but provides essential information on the user appliances, user habits and preferences. Even more, it does not completely consider appliances that are used for shorter time periods than $15 \mathrm{~min}$. (e.g., coffee machine, microware used not for cooking but warming up food, hairdryers etc.) or appliances that have a very specific consumption patterns with an average consumption far from the rated power (e.g.,

\subsection{Additional Information}

To properly analyse the consumption model of the target group, a more general approach is needed to describe the microenvironment. Consequently, several other information sources have been identified.

One of these sources is the local weather forecast for the UPB dorm location in Bucharest. The workgroup developing the consumption model has determined two local situation information necessities required for the dorm evaluation:

- Local natural lighting - in order to sim- fridge, boilers, most of small electronics). However, the consumption survey can be used as a baseline for the analysis, providing a maximal load curve that can be considered for comparison purposes.

Around 100 consumption surveys have been collected and individually analysed, assessing user indicated habits for day-today consumption changes. There changes based on user habits provide a variety in daily consumption and this information is used as the guideline for appliance model operation in Section 3.1.

ulate a natural lighting situation. Information on the natural lighting in Bucharest has been taken from an online source [12]. The information on this weather website divides the intensity of natural lighting into five shares - night, astronomical twilight, nautical twilight, civil twilight and daylight. For the purposes of sufficient natural lighting, the "daylight" data have been taken as the sufficient natural lighting moment. This provides the information of the natural 
lighting potential for a whole year and is important when modelling the lightning part of the load profile.

- Solar generation - the examined student dorms do not (yet) possess a PV panel solution, but in theory are capable to withstand PV panel deployment. This assumption is made based on the fact that faculty buildings built as part of the same architectural project already have this capability [13]. The solar generation information serves as the guideline of the potential PV panel generation, based on the local situation. The information on solar generation is collected from archived measurements using a 15-minute resolution and the data are available for locations near Romania [14].

\section{MODEL DEVELOPMENT}

\subsection{Auxiliary Models}

Auxiliary models use basic information and convert it into specific data, which then can be utilised as the key information for user consumption modelling.

\section{User Behaviour Model}

The user behaviour model generates the necessary reference of user daily activity. This information contains data on sleep periods, outdoor and home activity moment. Activity labelled "outside" refers to any activity the user engages in outside of his living space (including time spent at work or lectures), while label "home" indicates user availability at home, thereby potential contribution in overall building consumption.

The generation of individual user behaviour is based on their activities outside of their living space and combined with their sleep period, other moment is assumed as home activities and contribute to energy consumption. First, workday daily occupation is derived as the previously mentioned from the faculty schedule. Second, weekend occupation is generated by a randomized algorithm, selecting a random activity starting time and length. Through these solutions basic user daily activities are created. Additionally, it is assumed that every activity requires up to 1 hour additional time before and after every activity, (hour spent in transit or doing something else (e.g., grocery shopping, eating outside etc.). This additional activity is generated through a randomized algorithm. Last, a user sleep schedule is created and added. The daily sleep schedule is generated by an algorithm randomly selecting length between 6-9 hours and the selected period is analysed if it does not meet other daily activity posed limitations. Other time periods are marked as home activities and are used to model user consumption.

Table 2 shows an example of user behaviour. Top row represents the hours of a day, while the bottom row represents the activity's code. In the model, this information is generated by increments of 15 minutes, but for the example shown on a smaller resolution. The generated numerical values represent the actual data produced by the model and each value represents a different activity. Value " 0 " represents the sleep periods, "1" represents the home activity and " 2 " refers to the outside activity moments, color-coded blue, red and grey, respectively. 
Table 2. Hourly Activity Sample

\begin{tabular}{|c|c|c|c|c|c|c|c|c|c|c|c|c|c|}
\hline 9:00 & $10: 00$ & $11: 00$ & $12: 00$ & $13: 00$ & $14: 00$ & $15: 00$ & $16: 00$ & $17: 00$ & $18: 00$ & $19: 00$ & $20: 00$ & $21: 00$ & $22: 00$ \\
\hline 0 & 1 & 2 & 2 & 2 & 2 & 2 & 2 & 2 & 1 & 1 & 1 & 1 & 0 \\
\hline
\end{tabular}

\section{Daylight Model}

Daylight model organises the provided weather data regarding local natural lighting. The information gathered from online weather source is primarily divided into natural lighting degrees by their intensity. The portion that is used in the daylight model operation is the "daylight" portion, which occupies most of every day and is a sufficient lighting source. The result of this model is used to examine the energy savings provided by natural lighting prioritization over artificial lighting as a user aware- ness change.

The daylight model generates a data array with two values for each day of the year. These values depict the starting moment and the final moment the daylight period can be utilised as a lighting solution. In Table 3, an example of a single week and corresponding daylight period times are collected. The top values, in red, represent the starting time and the bottom ones, in blue, depict the ending time. These values have been converted into 24-hour form with hour and minute division, but in the model itself, these values are represented in minute form.

Table 3. Daylight Period Sample

\begin{tabular}{|c|c|c|c|c|c|c|}
\hline Mon. & Tue. & Wen. & Thu. & Fri. & Sat. & Sun. \\
\hline $8: 15$ & $8: 14$ & $8: 13$ & $8: 12$ & $8: 11$ & $8: 10$ & $8: 09$ \\
\hline $16: 30$ & $16: 32$ & $16: 34$ & $16: 36$ & $16: 38$ & $16: 40$ & $16: 42$ \\
\hline
\end{tabular}

\section{Appliance Model}

The appliance model is the most important user consumption part, which creates the user energy consumption individuality. The individuality is created by alteration in electrical appliance use, specified by the analysed users. Based on the conducted survey data, 24 appliance models have been developed. These models have been made using similar operation and control bases due to the survey data limitations, thereby models operate in 15-minute time steps.

The appliance model operates in two time periods - morning and evening, depicted in Fig. 2. These periods represent the time periods between sleep time and outside activities, and are divided into two in order to modify appliance operation habits. The periods are considered concrete for appliances that require direct user interaction - TV, PC etc., but can also be flexible for appliances that do require user interaction but can operate beyond any restrictions washing machine, phone charger etc. Furthermore, appliances operating in 24/7 schedule are not limited.

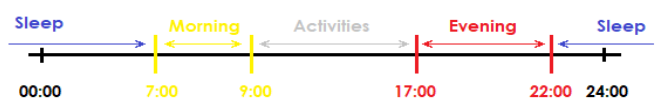

Fig. 2. Day period division.

Every appliance model uses a similar control setup and by control utilisation individual user appliance use habits can be depicted on a greater degree. There are 11 parameters for every appliance model, except 24/7 operation appliances using reduced power throughout the day: 
1. Appliance consumption - separated setting for morning/evening period. Sets appliance nominal operation power.

2. Minimum operation time - separated setting for morning/evening period with 15-minute step. Setting is used to set the minimal length the appliance is used.

3. Maximum operation time - separated setting for morning/evening period with 15-minute step. Setting is used to set the maximum length the appliance is used.

\subsection{Conclusive Models}

The conclusive models use generated information from all auxiliary models, providing the result of different information interaction. The developed models model individual user consumption, user awareness impact on consumption reduction and simulate renewable energy setup feasibility.

\section{User Consumption Model}

The user consumption model designs the individual user energy consumption by generating the energy consumption pattern. The pattern is generated taking into consideration user behaviour model information and appliance model information, which uses the individual user appliance use preferences.

The model operation combines multiple information sources, creating 48 unique user consumption patterns by using single consumption survey data combined with 48 university study schedules. This provides multiple users with similar appliance use preferences, but greatly different daily occupation times and in general impacts the overall user consumption. Furthermore, the modelled user consumption generated from similar preferences is not the same because of the changes in individual activities and different appliance daily use (operation window, utilisation start/end moments and
4. Appliance use chance - separated for morning/evening period. Sets appliance use frequency in the exact period.

5. Window of operation - separated settings for morning/evening period. Sets appliance operation limitation, due to a lack of available time.

6. Use period preference - combined morning/evening setting. Sets user preference in which period appliance is more likely to be used.

chance of using the appliance). The definition of unique outcomes from a single data source is done with randomized values. In the appliance settings, first, each appliance has a chance of being used; this chance impacts each user individually producing different outcomes. Second, each appliance has minimum and maximum operation time, which is selected randomly each time appliance is used; this is unique for every single time an appliance is used unless maximum and minimum values are the same. Last, each appliance has a randomly selected moment when a user starts to use it. This moment is made unique by two things: user availability, i.e., unique for each individual schedule and the random selected time, making the appliance operation times diverse between even the same settings.

Through a user consumption model, over 3000 unique user consumption patterns have been simulated. The simulated patterns are exclusive, since each generated pattern uses one combination of user behaviour and appliance preferences. This results in a large array of total consumption fluctuations among the user patterns with the smallest total consumption contributing to a six time smaller consumption than the largest total consumption contributor. This diversity is necessary to provide a greater 
variety of consumption, which will be used to represent an actual consumer group.

Following the user simulations, a randomized selection algorithm is used to choose a certain number of users matching a certain dorm inhabitant number (see Table 1). The users are randomly reselected until the simulated total user consumption practically matches the real student dorm consumption provided in Table 1. The final user selection closely reflects the actual inhabitants and is used in the test cases and the real consumer depiction.

\section{Appliance Consumption Reduction Model}

The appliance consumption reduction model tackles the task of exploring user awareness charge through simulation of energy use awareness increase in the form of consumption reduction of selected appliances. The consumption reduction algorithm can be divided into three distinct operation models that can address many appliances.

The first algorithm operation model for consumption reduction is for appliances that are used $24 / 7$ but should not be used in such an extended period of time. It means that it is necessary to use sleep mode or shut down appliances when they are not in use. The use mode is considered the one when the user is at the student dorm and is not sleeping, and periods of sleep and outside activity are the moments when the sleep mode or appliance shutdown is simulated.

The second algorithm operation model assumes that, by increased user awareness, the user will try to use certain appliances less, but without any reduction with regard to the comfort level, but the sleep mode or shutdown of an appliance is used when, for instance, two entertainment appliances are active or an appliance is not used for extended periods by taking breaks from time to time.

This last part of the algorithm is normally only used for lighting solutions, but is not limited to only this solution. This algorithm combines the daylight model and artificial lighting use with a goal to simulate user awareness change impacting users to use natural lighting over an artificial lighting solution when possible.

All algorithms work based on the same user awareness principles and explore user awareness impact on energy use by a gradual increase in awareness from 0 to $100 \%$ of the user involved. The gradual awareness increase is examined with a $5 \%$ step, giving the opportunity to see how each \% of population impacted would provide benefit because a $5 \%$ increase in awareness does not directly mean a $5 \%$ consumption reduction because of user activities, i.e., in one situation awareness might give a greater reduction than in another.

\section{PV Panel and Storage Unit Selection Model}

In order to achieve higher energy efficiency by consumption and carbon emission reduction, a feasibility study is performed by simulating the impact of the potential PV panel and energy storage (ES) solutions on an individual dorm situation.

The model of PV panel and storage unit selection carries out its calculations taking into account three boundaries. First, energy storage units are charged only by the PV panel over-generation. Second, the injection of excess PV panel generation towards the main grid is restricted. Last boundary is a physical limitation of area limited by the available roof space of individual dorm that is used for PV panel deployment.

The model simulates the added PV panel and energy storage achieved benefit 
by taking the consumption of a whole dorm, a sum of individual user consumption patterns, and reduced by the PV panel generation and storage unit, calculated based on solar generation reference. The consumption pattern and solar generation both use a 15-minute time step and the PV panel power generation overall efficiency is assumed to be $15 \%$, based on local PV panel generation reference. The goal of using PV panels and energy storage is to reduce the overall consumption; in the model, this is done through simulation of increasing PV panel generation and energy storage capacity. The model increases the PV panel generation by increased coverage, which is increased by 1 square meter per test and the increase in storage system is done by increasing the maximum capacity by $1 \mathrm{kWh}$ per test. The model tests every possible variation of PV panel size and storage capacity, with the main limitation being the available dorm roof area. Without additional boundaries the model will try to maximise the reduction of consumption by occupying all of the available roof space, which provides the result, but not efficiency. To achieve an appropriate result, one of the elements PV panel or storage - is bound to a value beforehand, thereby the model is required to only simulate the other non-specified element, limiting the non-realistic results. In the dorm testing, a dorm peak consumption value is used as the predetermined value for the bound element, providing a singular best result.

\section{NUMERICAL RESULTS}

\subsection{Power Energy Analysis}

The renewable energy solution feasibility of the student dorm building has been tested through the developed model. The solutions include the examination of optimal PV panel and ES system deployment based on peak energy consumption data, and they are aimed at increasing renewable energy share and reducing the building carbon emissions.

The feasibility of renewable energy setup is addressed for each dorm individually (see Table 4). In the process, the main three limitations are taken into account as well as the individual dorm peak consumption, which represents the size of the primarily chosen element in the two examined setup types:

- Type A - prioritization of PV panel peak generation. This type primarily selects PV panel peak generation and afterwards, through the model, selects the most appropriate ES capacity matching this generation.

- Type B - prioritization of ES capacity size. This type primarily selects the ES capacity and afterwards, through the model, selects the most appropriate PV panel size to match this storage capacity.

The modelled outcomes in Table 4 are depicted in percentage from original yearly consumption metered by the smart meter system. In the modelling process, two setup types have been examined and it has been concluded that Type B setup utilisation would provide the most optimal benefit, achieving around $58 \%$ consumption reduction with a margin of $\sim 1 \%$. All results show that a significant part of the PV panel generation is stored in the ES system, highlighting the necessity of this system. 
In the following KPI evaluation regarding the tested renewable setup feasibility, setup
Type B is used as the compared solution in Section 4.3.

Table 4. Renewable Energy Setup

\begin{tabular}{|c|c|c|}
\hline \multirow{2}{*}{$\begin{array}{l}\text { Dorm } 1 \\
(\text { Peak } 15.65 \mathrm{~kW})\end{array}$} & $\begin{array}{c}\text { Type A } \\
\text { PV } 16 \text { kW \& ES } 20 \text { kWh }\end{array}$ & $\begin{array}{c}\text { Type B } \\
\text { PV } 15.45 \text { kW \& ES } 16 \text { kWh }\end{array}$ \\
\hline & $\begin{array}{c}\text { Reduced: } 60.278 \% \\
26.645 \% \text { (Direct PV*) } \\
33.633 \% \text { (Storage) }\end{array}$ & $\begin{array}{c}\text { Reduced: } 59.129 \% \\
26.264 \% \text { (Direct PV*) } \\
32.865 \% \text { (Storage) }\end{array}$ \\
\hline \multirow{2}{*}{$\begin{array}{l}\text { Dorm } 2 \\
(\text { Peak 27,29 kW) }\end{array}$} & $\begin{array}{c}\text { Type A } \\
\text { PV } 27 \text { kW \& ES } 13 \text { kWh }\end{array}$ & $\begin{array}{c}\text { Type B } \\
\text { PV } 3.25 \mathrm{~kW} \& \text { ES } 27 \mathrm{kWh}\end{array}$ \\
\hline & $\begin{array}{c}\text { Reduced: } 48.5628 \% \\
24.444 \% \text { (Direct PV*) } \\
24.118 \% \text { (Storage) }\end{array}$ & $\begin{array}{c}\text { Reduced: } 58.005 \% \\
26.096 \% \text { (Direct PV*) } \\
31.909 \% \text { (Storage) }\end{array}$ \\
\hline \multirow{2}{*}{$\begin{array}{l}\text { Dorm } 3 \\
(\text { Peak } 26.52 \mathrm{~kW})\end{array}$} & $\begin{array}{c}\text { Type A } \\
\text { PV } 27 \text { kW \& ES } 14 \text { kWh }\end{array}$ & $\begin{array}{c}\text { Type B } \\
\text { PV } 31.20 \mathrm{~kW} \& \text { ES } 27 \mathrm{kWh}\end{array}$ \\
\hline & $\begin{array}{c}\text { Reduced: } 50.124 \% \\
25.069 \% \text { (Direct PV*) } \\
25.055 \% \text { (Storage) }\end{array}$ & $\begin{array}{c}\text { Reduced: } 57.921 \% \\
26.363 \% \text { (Direct PV*) } \\
31.558 \% \text { (Storage) }\end{array}$ \\
\hline \multirow{2}{*}{$\begin{array}{l}\text { Dorm } 4 \\
(\text { Peak } 32.70 \mathrm{~kW})\end{array}$} & $\begin{array}{c}\text { Type A } \\
\text { PV } 33 \text { kW \& ES } 15 \text { kWh }\end{array}$ & $\begin{array}{c}\text { Type B } \\
\text { PV } 40.5 \mathrm{~kW} \& \text { ES } 33 \mathrm{kWh}\end{array}$ \\
\hline & $\begin{array}{c}\text { Reduced: } 46.772 \% \\
24.178 \% \text { (Direct PV*) } \\
22.594 \% \text { (Storage) }\end{array}$ & $\begin{array}{c}\text { Reduced: } 57.402 \% \\
26.074 \% \text { (Direct PV*) } \\
31.328 \% \text { (Storage) }\end{array}$ \\
\hline
\end{tabular}

*Direct PV - generation from PV panels used when generated.

\subsection{User Awareness Analysis}

Regarding user awareness, the appliances examined by the developed model have been selected based on the potential to be impacted by user awareness changes. These selected appliances and cases can be seen in Table 5, depicting the situation of Dorm 4. The values, after user awareness column, represent the test case consumption share of the dorm total consumption taken from Table 1.

Test cases addressing user awareness are carried out for each dorm on an increasing $5 \%$ user awareness increments. This step size clearly depicts non-linear consumption impact due to high diversity in user appliance use habits. In Table 5, the main three degrees of user awareness are presented $0 \%$; $50 \% ; 100 \%$. The $0 \%$ degree represents the original consumption share without user awareness impact, while $100 \%$ degree represents the over-exaggerated awareness, depicting the potential maximum consumption reduction in a certain case. The $50 \%$ degree of user awareness is assumed as the achievable average awareness degree and the results at this degree are used in the evaluation (see Section 4.3). 
Table 5. Appliance Cases - Dorm 4

\begin{tabular}{|l|c|c|c|c|c|c|c|}
\hline Equipment & $\begin{array}{c}\text { Fluo. }{ }^{*} 25 \mathrm{~W} \\
\text { (Natural lighting) }\end{array}$ & $\begin{array}{c}\text { LED 10W } \\
\text { (Natural } \\
\text { lighting) }\end{array}$ & $\begin{array}{c}\text { Fluo. to } \\
\text { LED }\end{array}$ & $\begin{array}{c}\text { PC sleep } \\
\text { mode }\end{array}$ & $\begin{array}{c}\text { PC red. } \\
20 \%\end{array}$ & $\begin{array}{c}\text { TV red. } \\
20 \%\end{array}$ & $\begin{array}{c}\text { Kettle } \\
\text { red. } \\
30 \%\end{array}$ \\
\cline { 1 - 7 } User Awareness, \% & $11.9 \%$ & $4.8 \%$ & $11.9 \%$ & $33.4 \%$ & $33.4 \%$ & $15.1 \%$ & $3.7 \%$ \\
\hline $50 \%$ & $8.5 \%$ & $3.4 \%$ & $8.3 \%$ & $30.4 \%$ & $30.3 \%$ & $13.5 \%$ & $3.1 \%$ \\
\hline $100 \%$ & $5.1 \%$ & $2.0 \%$ & $4.8 \%$ & $26.5 \%$ & $26.7 \%$ & $12.1 \%$ & $2.6 \%$ \\
\hline
\end{tabular}

*Fluo. - Fluorescent light bulb.

Across all dorms, some similarities can be addressed. Some interchangeable results are "Natural lighting over Fluorescent" and "Fluorescent to LED conversion"; these are the results of any table in the 1st and 3rd column. The interesting result that can be highlighted is the conversion to LED lighting that provides a slightly larger consumption reduction than user's more efficient use of natural lighting. It provides valuable information that a user can provide sufficient saving only by using more efficient lighting without thinking of behaviour changes themselves. Furthermore, achieving a plausible $50 \%$ user awareness provides a theoretical $100 \%$ achievement, which can be made by the reduction created by some users converting to LED solution and other user behaviour changes to use natural lighting more efficiently. The end result of the combined different efforts provides around the same as $100 \%$ of the users switching to natural lighting use or $100 \%$ of the users converting to LED solution. Another major assessment is the inefficiency of optimised kettle use; although the appliance has a large consumption while operating, the total consumption over time is quite small and across all dorms the total consumption reduction of optimised use provides only half a percentage. This result indicates that in the tested cases the optimised kettle use does not provide large consumption savings and the solution will not be included in the final assessment. Column No. 2 "Natural lighting over LED" will also not be addressed in the final assessment because these results serve a means to the lighting solution efficiency comparison and highlight the best practice outcome.

Examination of appliance efficiency impact at $50 \%$ user awareness, 5 of the 7 simulated cases are listed by their overall consumption impact severity:

- Lighting solutions - lighting solution across all test cases provides most reduction in consumption. The largest reduction can be achieved (3.6-7.9\%) by converting to more efficient LED solutions, followed by the second largest reduction (3.4-7.6\%) through increased utilisation of natural lighting.

- PC solutions - PCs nowadays are widely used and this is especially true for university students. From the two tested cases, the most efficient reduction in PC consumption is the third best overall reduction (1.9-3.3\%) - reduced PC overall use by up to $20 \%$. Slightly less consumption reduction $(0-3 \%)$ is provided by the PC sleep mode use, but this solution in the overall reduction rates fourth. Sleep mode in Dorm 1 provides a $0 \%$ change due to the lack of excessive unattended PC usage by the model users.

- TV solution - many of the conducted surveys have indicated users having not only PCs as a frequently used appliance, but also TVs. The reduced consumption for this appliance ranks last - fifth, in the overall consumption reduction, but provides an optimal reduction of around $1.5 \%$. 


\subsection{Dorm Cross-Examination}

In the final examination, all four dorms are compared side by side. The comparison is observed through the selected KPIs, collected in Table 6. These selected KPIs represent the results with the largest impact on total consumption as well as give a general view. Table includes the KPI name, definition, calculation formula and represented units.

KPI resulting values are presented in Figs. 3 and 4. First five KPIs are based on the assumed achievable $50 \%$ degree of user awareness and the 7th KPI related to renewable energy assumes the best practice from the two available setup types.

Table 6. Compared KPIs

\begin{tabular}{|c|c|c|c|}
\hline No. & KPI & Definition & Metrics \\
\hline 1. & $\begin{array}{l}\text { Daylight Fluo- } \\
\text { rescent }\end{array}$ & $\begin{array}{l}\text { User's maximum utilisation of natural lighting to substitute Fluores- } \\
\text { cent electrical lighting solutions. Action impacted by User Awareness } \\
\text { increases the efficient energy use. }\end{array}$ & $\%$ \\
\hline 2. & $\begin{array}{l}\text { Fluorescent to } \\
\text { LED conver- } \\
\text { sion }\end{array}$ & $\begin{array}{l}\text { Improvement of efficiency through the use of a more efficient electri- } \\
\text { cal lighting solution. Action impacted by User Awareness increases } \\
\text { the efficient energy use. }\end{array}$ & $\%$ \\
\hline 3. & PC sleep mode & $\begin{array}{l}\text { Continuous unoccupied operation of PC creates a large increase in } \\
\text { consumption, when user does not use the PC directly. Increase in } \\
\text { User Awareness motivates user to switch to automatic sleep mode } \\
\text { when PC is unoccupied. }\end{array}$ & $\%$ \\
\hline 4. & $\begin{array}{l}\text { PC use reduc- } \\
\text { tion }\end{array}$ & $\begin{array}{l}\text { PC load can contribute to a large part of user's total consumption. } \\
\text { Increase in User Awareness regarding energy use may lead to reduc- } \\
\text { tion of appliance use by prioritization of other activities or sleep } \\
\text { mode utilisation while PC is not directly used. }\end{array}$ & $\%$ \\
\hline 5. & $\begin{array}{l}\text { TV use reduc- } \\
\text { tion }\end{array}$ & $\begin{array}{l}\text { TV load can contribute to a large part of user's total consumption. } \\
\text { Increase in User Awareness regarding energy use may lead to reduc- } \\
\text { tion of appliance use by prioritization of other activities or appliance } \\
\text { shutdown while TV is not directly used. }\end{array}$ & $\%$ \\
\hline 6. & $\begin{array}{l}\text { Energy con- } \\
\text { sumption }[15]\end{array}$ & $\begin{array}{l}\text { This indicator corresponds to the amount of energy consumed by the } \\
\text { end user. This consumption is calculated for a period of a single year } \\
\text { and used to assess end user energy efficiency. }\end{array}$ & $\%$ \\
\hline 7. & $\begin{array}{l}\text { Increase of } \\
\text { RES share [16] }\end{array}$ & $\begin{array}{l}\text { This indicator represents the degree at which household self-supplies } \\
\text { energy by renewable energy sources. Parameter provides the ratio of } \\
\text { self-supplied energy and total consumed, highlighting the degree of } \\
\text { independence. }\end{array}$ & $\%$ \\
\hline $8 . *$ & $\begin{array}{l}\text { Carbon dioxide } \\
\text { emissions [17] }\end{array}$ & $\begin{array}{l}\text { This indicator represents the } \mathrm{CO} 2 \text { emission share of Greenhouse Gas } \\
\text { emissions. Parameter reflects the amount of pollution. }\end{array}$ & $\%$ \\
\hline
\end{tabular}

* Value is assumed similar to the 7th KPI 
In Fig. 3 - Dorm 1, there is a unique singled out outcome of the four involved dorms. By achieving a degree of $50 \%$ user awareness, the overall dorm consumption from only changes in lighting solution reduces the total consumption by $15.5 \%$. It is a greater impact in comparison with the same solution savings of other dorms. More than half of these savings are achieved by converting current lighting solution with more efficient LED solutions $(7.9 \%)$; the other half is represented by user utilisation of natural lighting when possible (7.6\%). Additionally, unlike other dorm results, enabling PC sleep mode does not provide any consumption reduction; this does not limit the potential benefit, but in this case it is assumed that users are efficient, thereby PC sleep mode is enabled prior and no further changes can be applied. Although lighting solutions in Dorm 1 have a large potential of reducing the overall dorm consumption, the PC and TV solutions show a very low impact based on (from PC solu- tion there is a $1.9 \%$ reduction contribution and from TV up to $1.7 \%$ ) the dorm total yearly consumption. The percentage is large enough to provide a small impact, but in real consumption values Dorm 1 (in comparison with other three dorms) has from two to four times less consumption in a specific solution consumption reduction. The total dorm consumption reduction made by an increase in user awareness to $50 \%$ is equal to $19 \%$; this is the largest reduction share, but in actual consumption values the overall reduction of Dorm 1 is two - three times smaller than the results of other dorms. Dorm 1 is also the only dorm with the highest share of increased renewable energy share $(34.5 \%)$, where the lowest result is only $1.6 \%$ less for Dorm 4 . This result (like the previous mentioned) is the largest one in share, but the smallest one in actual power, with other renewable share size being two - three times larger. Similar change in carbon emissions can be expected as the increase in renewable energy share.
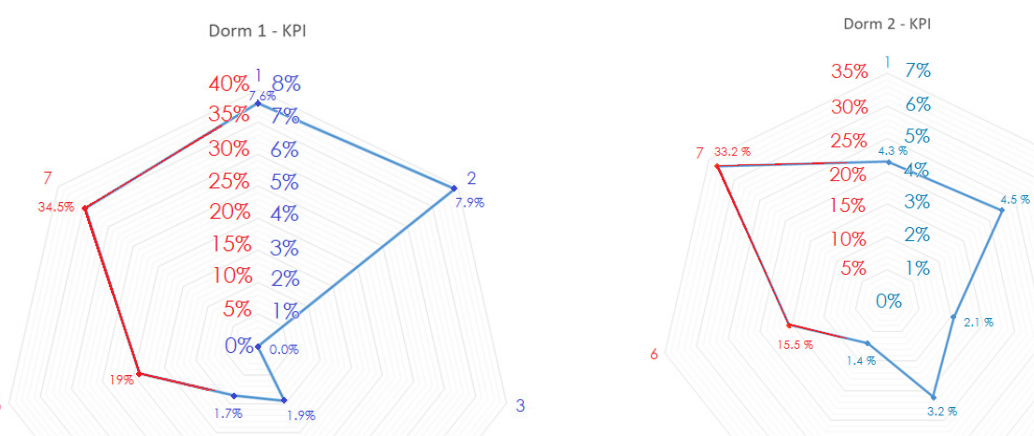

Fig. 3. KPI spider-web representation of Dorm $1 \& 2$.

In Figs. 3 and 4, Dorm 2 and Dorm 3 respectively represent a very similar situation. Similarities can be seen easily by the shape of the diagram itself; the two dorms share the same outline with a very small margin in values. By looking at yearly energy consumption (Table 1), more similarities can be seen with a $\sim 3 \%$ difference in dorm total consumption. The two situations label the middle results with no spe- 
cific unique outcomes. Comparing Dorm 2 and Dorm 3, the $\sim 3 \%$ difference can also be seen in values 1-5, where Dorm 3 has a slightly higher percentage, but the overall yearly consumption is slightly lower as well. In the end, Dorm 2 achieves an individual consumption reduction of $15.5 \%$ and Dorm 3 achieves $16.5 \%$. Although Dorm 3 achieves a $1 \%$ larger consumption reduction, this $1 \%$ share is equal to $\sim 3 \%$ in comparison with Dorm 2 in actual consumption. Thus, we can deduce that both dorms are very similar and all results have a difference of around $\sim 3 \%$ in actual power values. The only value that is greater for Dorm 2 is renewable energy share increase. Both dorms have the same $33.2 \%$ increase in renewable energy share; however, Dorm 2 has slightly greater consumption that is why this share in actual values is slightly greater. The expected change in the reduced carbon emissions is around $33.2 \%$ for each dorm.
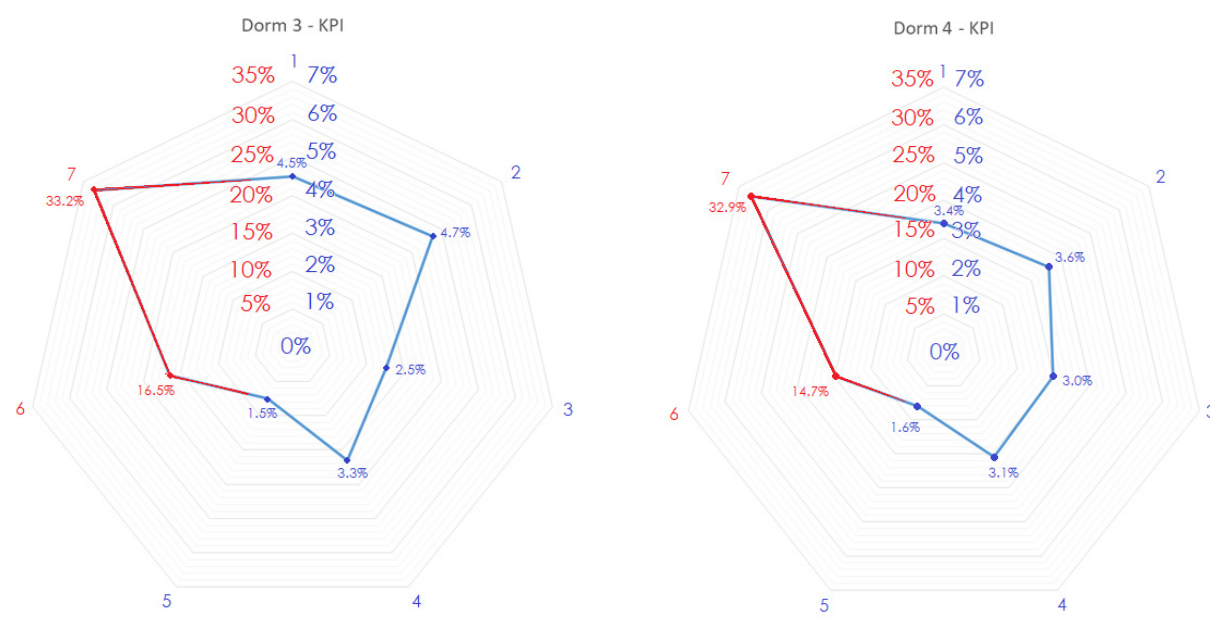

Fig. 4. KPI spider-web representation of Dorm $3 \& 4$.

In Fig. 4, Dorm 4 presents another unique outcome due to its large overall consumption. Dorm 4 is unique by providing some of the lowest values in categories where Dorm 1 thrives. Examining Dorm 4 lighting solutions, the largest benefit similar to other solutions is by efficient lighting solution utilisation - LED, with a $3.6 \%$ dorm consumption reduction; this is the lowest value in share, but per user it is similar to other dorms. For prioritization of natural lighting, the dorm can achieve a consumption reduction of $3.4 \%$, which as prior is also the lowest of any shares, but in actual value per person the result is fairly similar. Most impressive savings in Dorm 4 are pro- vided by utilisation of PC sleep mode with the largest share of any dorm (3\%) in dorm total consumption reduction. This value in dorm share is only $3 \%$, but taking into account actual consumption, where Dorm 4 consumption is three times larger than Dorm 1 or $50 \%$ larger than Dorm 2 or Dorm 3 , the value achieved provides large saving in overall consumption. The total reduction in the solutions used provides a $14.7 \%$ overall consumption reduction, which in share values is the lowest one, but in actual power values it is the greatest value of all four dorms. Additionally, in renewable share increase, Dorm 4 has scored $32.9 \%$, which similarly to other share results is the 
lowest one among the dorms, but it is $0.5-3$ times larger in actual power values. It indicates that the performed savings generated by user awareness increase and renewable energy solution provides a very large reduction in consumption in comparison with dorm large consumption and in general. The reduction in carbon emissions will be similar to the increased renewable share and due to dorm large overall consumption, it provides the greatest reduction in carbon emission in volume.

Across all four dorms, the renewable share has increased by around $33.5 \%$ with a margin of $1 \%$. This share increase is based on the calculated best outcome of the two setup types concluded in Section 4.1. This "best outcome" is based on individual dorm peak load, which is assumed as the value of PV panel size or ES capacity, depending on the setup type. In general, across all dorms the overall consumption reduction of around $58 \%$ with a margin of $1 \%$ has been achieved using prior determined superior "Type B" setup. Due to the resulting renewable energy consumption reduction, the prior known $42.7 \%$ (Table 1) renewable share for each dorm has increased by around $33.5 \%$, resulting in a very large theoretical renewable energy share. Additionally, each dorm has the potential to achieve around 14-19\% reduction in the overall consumption by implementing $50 \%$ degree of user awareness, which provides significant power savings on the part of end user. From all examined user awareness potential impact factors, the biggest power saving can be achieved in lighting solution modification, primarily from converting to more efficient light bulbs and secondly by wider utilisation of natural lighting.

\section{CONCLUSION}

The paper has addressed the topic of KPI evaluation on UPB student dorms through utilisation of the high-end smart meter system installed at the floor level. Taking into account the time constraints, KPI evaluation has been performed through energy consumption modelling means, and the comprehensive model has been developed using a multisource approach that has higher flexibility with its modular structure. This model is able to generate multiple individual user consumption patterns based on the information taken from consumption surveys and real smart meter measurements as a guideline. Using models flexibility has allowed simulating the impact of user awareness changes regarding a specific tested consumption case.

The developed consumption model has been used to simulate various users based on the available information of electric appliances, appliance use frequency and other preferences as well as individual user activities. Diversity in preferences and individual activity randomization has provided a large number of unique energy consumers and further grouped them together, representing the inhabitants of each dorm. The chosen group of representing inhabitants has been determined based on smart meter measurements. The representatives have been selected once and used in user awareness tests, as well as in the renewable energy setup feasibility study.

The UPB student dorm feasibility has been conducted from the user awareness perspective and renewable energy setup utilisation and depicted using KPI values. As a result of testing of renewable energy setups, it has been concluded that the supe- 
riority of "Type B" setup that prioritizes ES capacity selection is based on dorm peak load by providing most consumption reduction across all dorms. The utilisation of renewable energy setup, across all dorms, has provided an average of $58 \%$ in energy consumption reduction and increased the individual dorm renewable share by an average of $33.5 \%$. Similar percentage to increase renewable share can be expected in regards to carbon emission reduction. Furthermore, by achieving degree of $50 \%$ user awareness, the dorms have the potential to reduce their total yearly consumption by $14-19 \%$. The largest benefactor of user impact is lighting solutions with 3.6-7.9\% overall consumption reduction by using LED lighting and 3.4-7.6\% reduction by prioritizing natural lighting over artificial solutions.

Based on the evaluation of eight KPIs using a model approach, it has been concluded that great consumption reduction can be made on the user part and that every dorm has a great potential for reducing its individual total consumption and at the same time for increasing renewable energy share and reducing dorm carbon footprint by PV panel and ES system implementation.

\section{ACKNOWLEDGEMENTS}

The research has been carried out within the ERA Net-LAC 2nd Joint Call on Research and Innovation, project "An ICT Platform for Sustainable Energy Ecosystem in Smart Cities" (ITCity), ID: ELAC2015/ T10-0643, funded by the Latvian State Edu- cation Development Agency (VIAA) and the Romanian National Authority for Scientific Research and Innovation, CCCDIUEFISCDI, project ERAN-NET-LAC ITCity, within PNCDI III.

\section{REFERENCES}

1. Albino, V., Berardi, U., \& Dangelico, R. M. (2015). Smart Cities: Definitions, Dimensions, Performance, and Initiatives. Journal of Urban Technology, 22 (1), 3-21. DOI: $10.1080 / 10630732.2014 .942092$

2. Mutule, A., Teremranova, J., \& Antoskovs, N. (2018). Smart City through a Flexible Approach to Smart Energy. Latvian Journal of Physics and Technical Sciences, 55 (1), 3-14. DOI: 10.2478/lpts-2018-0001

3. Anthopoulos, L., Janssen, M., \& Weerakkody, V. (2015). Comparing smart cities with different modelling approaches. In Proceedings of the 24th International World Wide Web Conference (pp. 525-528). ACM. DOI: 10.1145/2740908.2743911
4. Badawya, M., Abd El-Aziza, A.A., Idress, A. M., Hefny, H., \& Hossam, S. (2016). A Survey on Exploring Key Performance Indicators. Future Computing ad Informatics Journal, 1 (1-2), 47-52. https:// doi.org/10.1016/j.fcij.2016.04.001

5. Bishop, D. A. (2018). Key Performance Indicators: Ideation to Creation. IEEE Engineering Management Review, 46 (1), 13-15. DOI: 10.1109/EMR.2018.2810104

6. Jeong, S., \&Yong-Woon, K. (2014). A holistic investigation method for data center resource efficiency. In 2014 International Conference on Information and Communication. DOI: 10.1109/ ICTC.2014.6983207 
7. UPB Campus Details (n.d.). Available at https://upb.ro/en/accommodation/ [5 September 2019]

8. Mutule, A., \& Teremranova, J. (2018). Introduction of Energy Saving Principles: Technologies and Awareness, Latvian Experience. Latvian Journal of Physics and Technical Sciences, 55 (6), 52-62. DOI: 10.2478/lpts-2018-0044

9. Toma, A.R., Olteanu, M.V., Gheorghe, C.M., \& Dumitrescu, A.-M. (2019). Electric energy consumption behavior of university students. In XIth International Symposium on Advanced Topics in Electrical Engineering. DOI: 10.1109/ATEE.2019.8724885

10. Transelectrica (Romanian TSO) Production Information (n.d.). Available at: http:// www.transelectrica.ro/en/web/tel/home [5 September 2019]

11. UPB Student Schedule 2018/2019 (n.d.). Available at: http://www.electro.pub.ro/ licen-ta/orar/ [30 September 2019]

12. Natural Lighting in Bucharest, Romania 2018/2019 (n.d.). Available at: https://www. timeanddate.com/sun/romania/bucharest [30 September 2019]

13. Craciunescu, A., Octavian Popescu, M., Laurenta Popescu, C., \& Ciumbulea, G. (2009). The PV grid-connected demonstration system of University "Politehnica" of Bucharest. In Proceedings of AFRICON 2009.
14. Information Platform, Data from 2018/2019 (n.d.). Available at: https://data.openpower-system-data.org/time_series [30 September 2019]

15. Bagnasco, A., Catanzariti, R., Coppi, L., Fresi, F., Silvestro, F., \& Vinci, A. (2017). Multi Facility Energy Monitoring in Medical Structures: Defining KPIs for Energy Saving and Exporting Best Practices. International Journal of Heat and Technology, 35 (1), 214-220. DOI: 10.18280/ijht.35Sp0130

16. Vasallo, A., Vallejo, E., Massa, G., Macia, A., Pablos, L., Criado, C., ... \& Larrinaga, F. (2019). The District Energy-Efficient Retrofitting of Torrelago. IOP Conference Series Earth and Environmental Science, 290, conference 1. DOI: 10.1088/17551315/290/1/012138

17. Hara, M., Nagao, T., Hannoe, S., \& Nakamura J. (2016). New Key Performance Indicators for a Smart Sustainable City. Sustainability, 8 (3), 206. https://doi. org/10.3390/su8030206 